Review of Income and Wealth

Series 54, Number 4, December 2008

\title{
POVERTY EQUIVALENT GROWTH RATE
}

\author{
BY NANAK KAKWANI \\ University of New South Wales \\ AND \\ Hyun H. SON* \\ Asian Development Bank
}

This paper proposes a new type of growth rate, called the "poverty equivalent growth rate" (PEGR), which takes into account both the growth rate in mean income and how the benefits of growth are distributed between the poor and the non-poor. The proposed measure satisfies a basic requirement that the proportional reduction in poverty is a monotonically increasing function of the PEGR. Thus, maximizing the PEGR implies a maximum reduction in poverty. The paper demonstrates that the magnitude of PEGR determines the pattern of growth: whether growth is pro-poor in relative or absolute sense or is "poverty reducing" pro-poor. The pattern of growth has been analyzed for Brazil using the National Household Survey (PNAD) covering the period 1995-2005.

\section{INTRODUCTION}

Reducing poverty has become a major concern in development policy. In turn, the focus on poverty reduction has spurred interest in pro-poor growth. This issue has generated a certain amount of policy and academic debate, ${ }^{1}$ which however, has not led to any consensus on how to define or measure pro-poor growth. This study aims to contribute to the literature of measuring pro-poor growth.

Kakwani and Pernia (2000) defined a growth as pro-poor if the poor benefit proportionally more than the non-poor, i.e. growth results in a redistribution of income in favor of the poor. When there is a negative growth rate, growth is defined as pro-poor if the loss from growth is proportionally less for the poor than for the non-poor. This is a relative concept of pro-poor growth because growth leads to a reduction in relative inequality. On the other hand, Grosse et al. (2008) have defined pro-poor growth in a stronger absolute sense: growth is pro-poor if the poor enjoy greater absolute benefits than the non-poor. When growth is negative, growth is absolute pro-poor if the absolute loss from growth is less for the poor than for the non-poor. Another definition of pro-poor growth is due to Ravallion and Chen (2003), who defined growth as pro-poor if it reduces poverty.

Note: To compute the poverty equivalent growth rate proposed in this paper, STATA do-file is available from the authors upon request. We would like to acknowledge helpful comments and suggestions by Stephan Klasen and two anonymous referees.

*Correspondence to: Hyun H. Son, Economics and Research Department, Asian Development Bank, PO Box 789, 0980 Manila, Philippines (hhson@adb.org).

${ }^{1}$ Among many others, see Dollar and Kraay (2002), Eastwood and Lipton (2001), McCulloch and Baulch (1999), Klasen (2003), Kakwani and Pernia (2000), Ravallion and Chen (2003) and Son (2004).

(C) 2008 The Authors

Journal compilation (C) 2008 International Association for Research in Income and Wealth Published by Blackwell Publishing, 9600 Garsington Road, Oxford OX4 2DQ, UK and 350 Main St, Malden, MA, 02148, USA. 
As will be demonstrated in this paper, this is the weakest definition of pro-poor growth when growth is positive. This definition does not specify how much the reduction in poverty should be in order to classify growth as pro-poor. However, when there is a negative growth rate, this is the strongest definition of pro-poor growth, i.e. the negative growth leads to a reduction in poverty. We will refer to this definition as poverty reducing pro-poor growth.

The focus on pro-poor growth is motivated by the fact that the growth process should achieve a rapid reduction in poverty. A change in poverty depends on both the growth rate in mean income and the distribution of the benefits from growth. Since there are two factors that affect poverty, the policy of maximization of growth rate alone will not achieve a maximum reduction in poverty.

In this paper, we will develop a new measure of growth rate called "poverty equivalent growth rate" (PEGR), which takes into account both the growth rate in mean income and how the benefits from growth are distributed between the poor and the non-poor. The proposed measure satisfies a basic requirement that reduction in poverty is a monotonically increasing function of the PEGR; the larger the PEGR, the greater the reduction in poverty will be. Thus, the PEGR is an effective measure of poverty reduction, i.e. maximization of PEGR implies a maximum reduction in poverty. If a government's objective is to achieve a maximum reduction in poverty, then its policies should be focused on maximizing the PEGR. Further the PEGR can be used as an important indicator to monitor poverty over time as well as across socioeconomic and demographic groups.

In the paper, we will also demonstrate that the magnitude of PEGR determines the pattern of growth; whether growth is pro-poor in a relative or absolute sense or is poverty reducing pro-poor. Thus, the PEGR provides a conceptual framework for unifying the three alternative concepts of pro-poor growth.

The PEGR is derived for an entire class of additively decomposable poverty measures-including the Foster-Greer-Thorbecke (Foster et al., 1984) and Watts (1968) measures. Ravallion and Chen (2003) derived their measure of growth rate only for the Watts measure. Thus, the PEGR is more general in the sense that it encompasses all additively decomposable poverty measures. ${ }^{2}$ Furthermore, while Ravallion and Chen's measure does not satisfy the basic monotonicity axiom, the PEGR satisfies the axiom.

This paper is structured in the following manner. Section 2 is devoted to the conceptual framework. Section 3 defines the poverty equivalent growth rate. In Section 4, the pattern of growth is analyzed for Brazil using the National Household Survey (PNAD) covering the period 1995-2005. Section 5 concludes.

\section{Conceptual Framework}

Suppose the income $x$ of an individual is a random variable with a density function $f(x)$, and $z$ is the poverty line, then a general class of additively decomposable poverty measures can be written as

${ }^{2}$ Kakwani and Pernia (2000) and McCulloch and Baulch (1999) measures of pro-poor growth focus only on the distribution of benefits of growth between the poor and the non-poor. Ravallion and Chen (2003) is the only measure in the literature which is comparable to the proposed PEGR. 


$$
\theta=\int_{0}^{z} P(z, x) f(x) d x
$$

where $P(z, x)$ is a homogenous function of degree zero in $z$ and $x$ such that ${ }^{3}$

$$
P(z, z)=0, \frac{\partial P(z, x)}{\partial x}<0 \text { and } \frac{\partial^{2} P(z, x)}{\partial x^{2}}>0 .
$$

The growth elasticity of poverty is defined as the ratio of the proportional change in poverty to the proportional change in the mean income. This elasticity is obtained by the total differential of (1) as

$$
\delta=d \operatorname{Ln}(\theta) / \gamma=\frac{1}{\theta \gamma} \int_{0}^{H} \frac{\partial P}{\partial x} x(p) g(p) d p
$$

where $\gamma=d \operatorname{Ln}(\mu)$ is the growth rate of mean income and $g(p)=d \operatorname{Ln}(x(p))$ is the growth rate of the income of people at the $p$-th percentile. $\delta$ is the percentage change in poverty resulting from a growth rate of 1 percent in the mean income.

Poverty reduction depends on two factors. The first is the magnitude of the economic growth rate: the larger the growth rate, the greater the reduction in poverty. The second is the change in inequality. Growth is generally accompanied by changes in inequality; an increase in inequality reduces the impact of growth on poverty reduction. To measure these two impacts, we decompose the growth elasticity of poverty in (2) as the sum of two components, $\eta$ and $\zeta$ :

$$
\delta=\eta+\zeta
$$

where $\eta=\frac{1}{\theta} \int_{0}^{H} \frac{\partial P}{\partial x} x(p) d p$ is the neutral relative growth elasticity of poverty derived by Kakwani (1993). This is the percentage change in poverty when there is a 1 percent growth in the mean income of society, provided that the growth process does not change relative inequality (i.e. when everyone in society receives the same proportional benefits of growth). This elasticity is always negative. $\zeta$ is given by

$$
\zeta=\frac{1}{\theta \gamma} \int_{0}^{H} \frac{\partial P}{\partial x} x(p) d \operatorname{Ln}\left(L^{\prime}(p)\right) d p
$$

where $L^{\prime}(p)$, being the first derivative of the Lorenz function, measures the effect of inequality on poverty reduction. This tells us how poverty varies due to changes in relative inequality that accompany the growth process. Growth is pro-poor

${ }^{3}$ Foster-Greer-Thorbecke (Foster et al., 1984) poverty measures are obtained when we substitute $P(z, x)=\left(\frac{z-x}{z}\right)^{\alpha}$ in (1), where $\alpha$ is the parameter of inequality aversion. When $\alpha=0$, 1 , or 2 , the poverty measure $\theta$ corresponds to the head-count ratio, the poverty gap ratio or the severity of poverty index, respectively. If we substitute $P(z, x)=\operatorname{Ln}(z)-\operatorname{Ln}(x)$ in (1), we obtain the Watts (1968) poverty measure. 
(anti-poor) in a relative sense if the change in relative inequality that accompanies growth reduces (increases) the total poverty. ${ }^{4}$ That is to say, growth is pro-poor (anti-poor) if the growth elasticity of poverty is greater (less) than the neutral relative growth elasticity of poverty.

Using such ideas, Kakwani and Pernia (2000) developed a relative pro-poor growth index defined as the ratio of the growth elasticity of poverty to the neutral relative growth elasticity of poverty:

$$
\varphi=\frac{\delta}{\eta} .
$$

From this, a growth process is said to be pro-poor in a relative sense if $\varphi$ is greater than 1. If the growth rate is negative, growth is defined as relatively pro-poor if $\varphi$ is less than 1, i.e. loss of income from negative growth is proportionally less for the poor than for the non-poor. In addition, a growth process is defined as neutral in relative distribution if $\varphi=1$, i.e. when everyone enjoys the same proportional benefits.

We may define a growth process as "absolutely pro-poor" when the poor receive the absolute benefits of growth equal to or more than the absolute benefits received by the non-poor. Following this approach, absolute inequality would fall during the course of growth. Similar to the idea of neutral relative growth elasticity of poverty, we introduce the idea of neutral absolute growth elasticity of poverty, which is defined as the elasticity of poverty with respect to growth when the benefits of growth are equally shared by every individual in society. This elasticity is given by

$$
\eta^{*}=\frac{\mu}{\theta} \int_{0}^{H} \frac{\partial P}{\partial x} d p
$$

which is the proportional change in poverty given a 1 percent growth in the mean income of society, provided that the growth process does not change absolute inequality (i.e. when everyone in society receives the same absolute benefits of growth). It can be shown that the absolute magnitude of $\eta^{*}$ is always greater than the absolute magnitude of $\eta$, which implies that poverty reduction will always be greater when people receive equal absolute benefits rather than equal proportional benefits from the same level of economic growth.

Similar to the idea of Kakwani and Pernia's (2000) relative pro-poor growth index, we define an absolute pro-poor growth index as:

$$
\varphi^{*}=\frac{\delta}{\eta^{*}} .
$$

\footnotetext{
${ }^{4}$ Many studies measure the pro-poorness of growth by changes in the Gini index. The Gini index is not an appropriate measure of inequality to measure pro-poor growth because there is no monotonic relationship between changes in the Gini index and poverty reduction. With mean income remaining the same, an increase or a decrease in the Gini index can still leave poverty unchanged; similarly, an increase or a decrease in the Gini index can lead to a reduction or an increase in poverty. Thus, a change in the Gini index cannot always tell us whether or not growth is pro-poor. In this context, $\varsigma$ defined above has a direct relationship with changes in poverty. This is derived from the part of the Lorenz curve which directly affects the poor.
} 
A growth process will be pro-poor in the absolute sense if $\varphi^{*}$ is greater than 1 . If the growth rate is negative, growth is defined as absolute pro-poor when $\varphi^{*}$ is less than 1, i.e. absolute loss of income from negative growth is less for the poor than for the non-poor.

According to Ravallion and Chen (2003), growth is pro-poor if it reduces poverty, i.e. $d \operatorname{Ln}(\theta)=\delta \gamma$ is less than 0 . We have identified this situation as poverty reducing pro-poor growth.

So far, we have discussed three alternative concepts of pro-poor growth. In the next section, we integrate these concepts into a common framework based on the PEGR.

\section{Poverty Equivalent Growth Rate}

The two indices of pro-poor growth, $\varphi$ and $\varphi^{*}$, merely measure how the benefits from growth are distributed across the population. They are not sufficient to determine any change in poverty. To determine how a growth process affects poverty, we need to have an indicator that takes account of both the growth rate in mean income and the distribution of benefits from growth.

To address this issue, we introduce the idea of a poverty equivalent growth rate (PEGR). It is the growth rate $\gamma^{*}$ that would result in the same proportional change in poverty as the present growth rate $\gamma$ if the growth process was not accompanied by any change in relative inequality (i.e. when everyone in society received the same proportional benefits of growth). The actual proportional change in poverty is given by $\delta \gamma$, where $\delta$ is the growth elasticity of poverty. If growth were distributionneutral in a relative sense (i.e. relative inequality did not change), then the growth rate $\gamma^{*}$ would achieve a proportional change in poverty equal to $\eta \gamma^{*}$ which should be equivalent to $\delta \gamma$. Thus, the PEGR denoted by $\gamma^{*}$ is given by

$$
\gamma^{*}=(\delta / \eta) \gamma=\varphi \gamma
$$

which can also be written as

$$
\gamma^{*}=\frac{\int_{0}^{H} \frac{\partial P}{\partial x} x(p) g(p) d p}{\int_{0}^{H} \frac{\partial P}{\partial x} x(p) d p}
$$

which shows that the PEGR as the weighted average of the growth rates of income at each percentile point, with the weight depending on the poverty measure used. ${ }^{5}$

${ }^{5}$ For the Foster-Greer-Thorbecke (Foster et al., 1984) class of poverty measures, the PEGR is given by

$$
\gamma_{\alpha}^{*}=\int_{0}^{H}\left(\frac{z-x(p)}{z}\right)^{\alpha-1} x(p) g(p) d p / \int_{0}^{H}\left(\frac{z-x(p)}{z}\right)^{\alpha-1} x(p) d p \text { for } \alpha \geq 1
$$

The PEGR for the Watts measure is obtained by substituting $P(z, x)=\operatorname{Ln}(z)-\operatorname{Ln}(x)$ into (7) and can be defined as $\gamma_{W}^{*}=\frac{1}{H} \int_{0}^{H} g(p) d p$. This is, in fact, the pro-poor growth index proposed by Ravallion and Chen (2003). 
Since $\eta$ is always negative, equation (7) implies that if $\delta \gamma$ is negative (positive), $\gamma^{*}$ will be positive (negative). Equivalently, the PEGR is consistent with the direction of the change in poverty: a positive (negative) value of the PEGR implies a reduction (increase) in poverty. ${ }^{6}$ The proposed measure thus satisfies a basic requirement that the reduction in poverty is a monotonically increasing function of the PEGR; the larger the PEGR, the greater the reduction in poverty will be. Thus, the PEGR is an effective measure of poverty reduction, i.e. maximization of PEGR implies a maximum reduction in poverty.

To determine the pattern of growth, i.e. whether growth is pro-poor or anti-poor, write

$$
\gamma^{*}=\gamma+(\varphi-1) \gamma
$$

As noted earlier, growth is pro-poor in relative sense when $\gamma>0$ and $\varphi>1$ or when $\gamma<0$ and $\varphi<1$. Each of these conditions implies that the second term in the right hand side of (9) is positive. Thus, growth will be pro-poor in a relative sense if $\gamma^{*}>\gamma$.

To determine if growth is pro-poor in absolute sense, write equation (9) as

$$
\gamma^{*}=\gamma\left[1+\left(\varphi-\varphi^{*}\right)\right]+\left(\varphi^{*}-1\right) \gamma
$$

As defined earlier, growth is pro-poor in the absolute sense when $\gamma>0$ and $\varphi^{*}>1$ or when $\gamma<0$ and $\varphi^{*}<1$. Each of these conditions implies that the second term in the right hand side of $(10)$ is positive. Thus, growth will be pro-poor in the absolute sense if $\gamma^{*}>\gamma\left[1+\left(\varphi-\varphi^{*}\right)\right]$ Since $\varphi>\varphi^{*}$ always holds, pro-poor growth in the absolute sense will always imply pro-poor growth in the relative sense but not the other way around. Thus, the absolute pro-poor growth is a stronger requirement than the relative pro-poor growth. This suggests that with the same growth rate in mean income, the absolute pattern of growth will lead to a more rapid reduction in poverty than the relative pattern of growth.

The Ravallion and Chen (2003) definition of pro-poor growth implies that growth reduces poverty, which is satisfied when $\gamma^{*}>0$. If growth rate $\gamma>0$, then $\gamma^{*}>\gamma$ will always imply $\gamma^{*}>0$, and thus the relative pro-poor growth always implies a poverty reducing pro-poor growth. This demonstrates that poverty reducing pro-poor growth is the weakest requirement, weaker than both relative and absolute pro-poor growth, when growth rate is positive. On the other hand, $\gamma^{*}>0$ implies that $\gamma^{*}-\gamma>-\gamma$, which further implies $\gamma^{*}>\gamma$ when $\gamma<0$. This demonstrates that poverty reducing pro-poor growth is a stronger requirement than the relative pro-poor growth when the growth rate in mean income is negative. Applying the same logic, we can show that poverty reducing pro-poor growth is a stronger requirement than even the absolute pro-poor growth when the growth rate in mean income is negative. Thus, the PEGR provides a unifying framework to determine the patterns of growth defined by three alternative concepts of pro-poor growth.

${ }^{6}$ The PEGR satisfies the consistency axiom proposed by Ravallion and Chen (2003). 
Inequality is commonly perceived as a relative concept because there are few studies that present absolute measures of inequality. We can thus expect that there will be a greater consensus on a relative, rather than an absolute concept of pro-poor growth. However, an absolute concept of pro-poor growth can also be attractive since government transfer policies are generally understood in terms of absolute benefits going to the poor. For instance, a policy that gives $\$ 5$ to the poor and $\$ 1$ to the rich will be readily accepted as pro-poor. Such a policy will be absolutely pro-poor. On the other hand, a policy that gives $\$ 1$ to the poor and $\$ 5$ to the rich will never be regarded as pro-poor, even though it may reduce poverty. This suggests that the concept of poverty reducing pro-poor growth may not be considered as an appropriate definition of pro-poor growth because it classifies growth as pro-poor even when the poor receive a tiny fraction of benefits of growth that are enjoyed by the rich.

Son and Kakwani (2008) conducted a cross-country analysis of pro-poor growth in 80 countries in 237 growth spells during the period 1984-2001. They found 106 spells and 131 spells for negative growth rates and positive growth rates, respectively. The incidence of poverty fell in 86 percent of all positive growth spells and increased in 87 percent of all negative growth spells. These results point out that most growth processes will be classified as pro-poor (anti-poor) using the definition of poverty reducing pro-poor growth, provided that the growth rate in mean income is positive (negative). This implies that governments can achieve pro-poor outcomes only by ensuring positive growth rates. Such outcomes may not guarantee a rapid reduction in poverty if the growth process leads to increases in relative and absolute inequalities. A main objective of having pro-poor growth is to achieve a rapid reduction in poverty. With this objective to the fore, the focus of government policies should be on both enhancing growth and improving relative and absolute inequality, i.e. maximizing the PEGR.

\section{EMpirical Illuustration}

This study utilizes the Pesquisa Nacional por Amostra de Domicilios (PNAD, the Brazilian Annual National Household Survey) from 1995 to 2005. For this study, we have chosen per capita real income as a welfare indicator. ${ }^{7}$ Per capita real income is defined as the per capita nominal income adjusted for prices, which vary across regions and over time. This is achieved by dividing the per capita nominal income by the per capita poverty line expressed as a percentage. The poverty line used in this paper takes into account the variation in regional costs of living (Neri, 2001; Ferreira et al., 2003). ${ }^{8}$

\footnotetext{
${ }^{7}$ Almost all poverty and inequality studies in Latin American countries use per capita income as a measure of household welfare. This is because their household surveys are designed to collect data on income more accurately than data on expenditures. Moreover, many surveys in Latin America provide detailed expenditures only for selected years.

${ }^{8}$ The poverty line in Brazil is the income required to meet the basic needs in food and non-food items of consumption.
} 
TABLE 1

Poverty Equivalent Growth Rates fOR Brazil, 1995-2005

\begin{tabular}{lcccc}
\hline \hline & & \multicolumn{2}{c}{ Poverty Equivalent Growth Rate (PEGR) } \\
\cline { 3 - 5 } Period & Actual Growth Rate & Head-Count Ratio & Poverty Gap & Severity of Poverty \\
\hline $1995-96$ & 1.59 & 0.66 & -3.16 & -5.63 \\
$1996-97$ & 0.70 & -0.01 & 1.96 & 2.87 \\
$1997-98$ & 0.87 & 3.12 & 4.50 & 5.82 \\
$1998-99$ & -5.12 & -2.90 & -1.86 & -1.32 \\
$1999-01$ & 0.77 & 1.08 & -0.53 & -1.59 \\
$2001-02$ & 0.07 & 0.60 & 6.20 & 9.17 \\
$2002-03$ & -6.13 & -2.40 & -3.36 & -5.77 \\
$2003-04$ & 3.55 & 7.55 & 9.26 & 12.26 \\
$2004-05$ & 5.58 & 9.19 & 8.35 & 9.19 \\
\hline
\end{tabular}

Source: Authors' calculations.

Table 1 presents growth rates of per capita real income as well as the PEGR. ${ }^{9}$ The results reveal that the actual growth rate of per capita real income was almost stagnant from 1995 to 2002. However, growth improved during the last two periods, with per capita real income increasing at an annual rate of 3.55 and 5.58 percent during 2003-04 and 2004-05, respectively.

We also look at how the benefits (losses) from growth are distributed among the poor and the non-poor. This analysis can be done using the PEGR calculated for a general class of Foster-Greer-Thorbecke (Foster et al., 1984) poverty measures (see Table 1). It is clear from Figure 1 that the growth pattern in Brazil has been mostly pro-poor for the past decade except for the 1995-96 period. This is observed from the fact that the PEGR is greater than the actual growth rate in per capita real income. The findings suggest that overall, the growth in Brazil, although slow and sluggish, benefited the poor proportionally more than the non-poor during the 1995-2005 period.

It is also interesting to note from Table 1 that when there was positive growth, it benefited the ultra-poor living far below the poverty line much more than the poor clustered around the poverty line. This is indicated by the values of the PEGR for the severity of poverty index. This type of growth pattern can be observed from the periods 1997-98, 2001-02, 2003-04 and 2004-05.

The pro-poor growth pattern can also be examined when the economy goes through a period of negative growth. With negative growth, and a PEGR greater (less) than the actual growth rate, the recession hurts the poor (non-poor) proportionally less than the non-poor (poor). To illustrate, following the Asian crisis during the period 1998-99, there was a substantial fall in per capita real income. However, its adverse effect was felt proportionally less among the poor (and even much less among the ultra-poor) than the non-poor. Another period of negative growth occurred during 2002-03, due mainly to a confidence shock to the market from the new administration. In that period, while the negative growth hurt the

${ }^{9}$ We did not calculate the PEGR for the Watts measure because some households in the sample had zero incomes. This is the major problem with the Watts measure. One possible solution to this problem is to exclude households with zero incomes. However, we did not think that this was an appropriate solution because deleting such households introduces bias in the estimates. Moreover, we do not believe that the Watts measure will provide greater insight into the issue than the three poverty measures used in our calculations. 


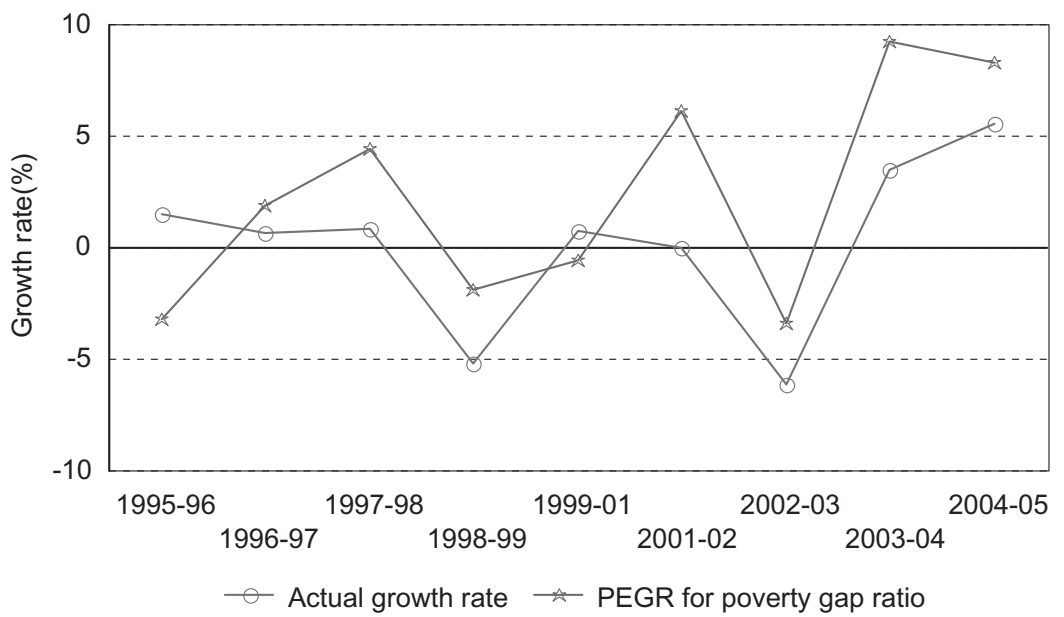

Figure 1. Poverty Equivalent Growth Rate for the Poverty Gap Ratio

poor proportionally less than the non-poor, its adverse impacts were much greater on the ultra-poor compared to poor people living just below the poverty line.

We have so far looked at the pattern of growth in relative terms. Do the poor benefit from growth in absolute terms? Table 2 presents a summary of patterns of growth in terms of three alternative concepts of pro-poor growth discussed in the previous sections. The results reveal that overall the poor have not gained in absolute terms during the 1995-2005 periods. Yet there are exceptions for two sub-periods when the poor lost absolutely less than the non-poor. Those exceptions occurred when growth was negative. In 1998-99 and 2002-03, absolute losses from negative growth were smaller for the poor than for the non-poor.

During the economic recovery in the 2003-05 period, the poor enjoyed greater proportional benefits of growth but their absolute benefits were smaller; growth was not pro-poor in the absolute sense. To achieve a rapid reduction in poverty, the government should aim at achieving absolute pro-poor growth. This has a greater impact on poverty reduction than the relative pro-poor growth.

The negative growth generally increases poverty unless the reduction in inequality offsets the adverse impact of negative growth, which is less likely to happen. In the two negative growth periods, 1998-99 and 2002-03, poverty increased. Based on the definition of poverty reducing pro-poor growth, this growth pattern is classified as anti-poor. This definition of pro-poor growth does not tell us how the loss of income incurred from the negative growth rate is distributed between the poor and the non-poor. The relative and absolute propoor patterns inform us that the loss of income is less for the poor than for the non-poor in both relative and absolute terms.

\section{Concluding Remarks}

Poverty reduction depends on two factors. The first factor is the magnitude of the economic growth rate: the larger the growth rate, the greater the reduction of 
TABLE 2

Patterns of Growth in BraZiL

\begin{tabular}{|c|c|c|c|}
\hline Periods & $\begin{array}{l}\text { Relative Pro-Poor } \\
\text { Growth }\end{array}$ & $\begin{array}{l}\text { Absolute Pro-Poor } \\
\text { Growth }\end{array}$ & $\begin{array}{l}\text { Poverty Reduction } \\
\text { Pro-Poor Growth }\end{array}$ \\
\hline \multicolumn{4}{|c|}{ Head count ratio } \\
\hline $1995-96$ & No & No & Yes \\
\hline 1996-97 & No & No & No \\
\hline 1997-98 & Yes & Yes & Yes \\
\hline 1998-99 & Yes & Yes & No \\
\hline 1999-01 & Yes & No & Yes \\
\hline 2001-02 & Yes & Yes & Yes \\
\hline $2002-03$ & Yes & Yes & No \\
\hline 2003-04 & Yes & No & Yes \\
\hline 2004-05 & Yes & No & Yes \\
\hline \multicolumn{4}{|c|}{ Poverty gap ratio } \\
\hline $1995-96^{\circ}$ & No & No & No \\
\hline 1996-97 & Yes & No & Yes \\
\hline $1997-98$ & Yes & No & Yes \\
\hline 1998-99 & Yes & Yes & No \\
\hline 1999-01 & No & No & No \\
\hline 2001-02 & Yes & Yes & Yes \\
\hline $2002-03$ & Yes & Yes & No \\
\hline 2003-04 & Yes & No & Yes \\
\hline $2004-05$ & Yes & No & Yes \\
\hline \multicolumn{4}{|c|}{ Severity of poverty } \\
\hline 1995-96 & No & No & No \\
\hline 1996-97 & Yes & No & Yes \\
\hline 1997-98 & Yes & No & Yes \\
\hline 1998-99 & Yes & Yes & No \\
\hline 1999-01 & No & No & No \\
\hline 2001-02 & Yes & Yes & Yes \\
\hline $2002-03$ & Yes & Yes & No \\
\hline 2003-04 & Yes & No & Yes \\
\hline 2004-05 & Yes & No & Yes \\
\hline
\end{tabular}

Source: Authors' calculations.

poverty. The second is the distribution of benefits from economic growth between the poor and the non-poor. Since there are two factors that affect poverty, the policy of maximization of growth rate alone will not achieve a maximum reduction in poverty. Our emphasis in this paper is the need to enhance growth and improve the distribution of benefits from growth.

This paper develops a new measure of growth rate called the "poverty equivalent growth rate" (PEGR), which takes into account both the growth rate in mean income and how the benefits from growth are distributed between the poor and the non-poor. The proposed measure satisfies a basic requirement that reduction in poverty is a monotonically increasing function of the PEGR; the larger the PEGR, the greater will be the reduction in poverty. Thus, the PEGR is an effective measure of poverty reduction (maximization of PEGR implies a maximum reduction in poverty). If a government's objective is to achieve a maximum reduction in poverty, then its policies should be focused on maximizing the PEGR.

The paper demonstrates how the magnitude of PEGR can determine the pattern of growth; whether growth is pro-poor or anti-poor. The paper presents 
three alternative definitions of pro-poor growth, i.e. relative pro-poor growth, absolute pro-poor growth and poverty reducing pro-poor growth. There is no consensus in the literature on defining the pro-poor growth. This paper argues that all three definitions are important in understanding the patterns of growth and the PEGR provides a unifying conceptual framework to determine the patterns of growth using three alternative definitions of pro-poor growth.

The empirical illustration presented in the paper suggests that while growth in Brazil had been sluggish over the period 1995-2005, it generally benefited the poor proportionally more than the non-poor. The PEGR can also be utilized to examine a pattern of growth when the economy goes through episodes of negative growth. Following the Asian financial crisis in 1998-99, Brazil suffered a substantial fall in per capita real income, yet its adverse effect was felt proportionally less among the poor (and even much less among the ultra-poor) than the non-poor. There was another period of negative growth during 2002-03, which stemmed largely from a confidence shock to the market caused by the installation of a new administration in the country. During that period, while the negative growth hurt the poor proportionally less than the non-poor, its adverse impacts were felt much greater by the ultra-poor compared to poor people living just below the poverty line.

During the economic recovery in the 2003-05 period, the poor enjoyed greater proportional benefits of growth but their absolute benefits were lower; growth was not pro-poor in the absolute sense. To achieve a rapid reduction in poverty, the government should aim at achieving absolute pro-poor growth, which has a greater impact on poverty reduction than relative pro-poor growth.

\section{Appendix: How to Calculate the Poverty Equivalent Growth Rate?}

A general class of poverty measure $\theta$ given in (1) is fully characterized by the poverty line $z$ and the vector of income distribution $\tilde{x}$ :

$$
\theta=\theta(z, \tilde{x})
$$

Suppose the income distributions (adjusted for prices) in the initial and terminal years are $\tilde{x}_{1}$ and $\tilde{x}_{2}$ with mean incomes $\mu_{1}$ and $\mu_{2}$, respectively, then an estimate of the growth elasticity of poverty $\delta$ can be obtained by

$$
\hat{\delta}=\left(\operatorname{Ln}\left[\theta\left(z, \tilde{x}_{2}\right)\right]-\operatorname{Ln}\left[\theta\left(z, \tilde{x}_{1}\right)\right]\right) / \hat{\gamma}
$$

where $\hat{\gamma}$ given by

$$
\hat{\gamma}=\operatorname{Ln}\left(\mu_{2}\right)-\operatorname{Ln}\left(\mu_{1}\right)
$$

is an estimate of the growth rate of mean income.

An estimate of PEGR is given by

$$
\hat{\gamma}^{*}=(\hat{\delta} / \hat{\eta}) \hat{\gamma}
$$


where $\hat{\eta}$ is an estimate of the neutral relative growth elasticity of poverty, which should satisfy equation (3):

$$
\hat{\delta}=\hat{\eta}+\hat{\zeta}
$$

where $\hat{\zeta}$ is an estimate of the effect of inequality on poverty reduction. Kakwani's (2000) poverty decomposition methodology can then be used to calculate $\hat{\eta}$ and $\hat{\zeta}$ using the following formulae: ${ }^{10}$

$$
\hat{\eta}=\frac{1}{2}\left[\ln \left(\theta\left(z, \mu_{2} \tilde{x}_{1} / \mu_{1}\right)\right)-\ln \left(\theta\left(z, \tilde{x}_{1}\right)\right)+\ln \left(\theta\left(z, \tilde{x}_{2}\right)\right)-\ln \left(\theta\left(z, \mu_{1} \tilde{x}_{2} / \mu_{2}\right)\right)\right] / \hat{\gamma}
$$

and

$$
\hat{\zeta}=\frac{1}{2}\left[\ln \left(\theta\left(z, \mu_{1} \tilde{x}_{2} / \mu_{2}\right)\right)-\ln \left(\theta\left(z, \tilde{x}_{1}\right)\right)+\ln \left(\theta\left(z, \tilde{x}_{2}\right)\right)-\ln \left(\theta\left(z, \mu_{2} \tilde{x}_{1} / \mu_{1}\right)\right)\right] / \hat{\gamma}
$$

This methodology can be used to estimate the PEGR for the entire class of poverty measures given in (1).

The proportional reduction in poverty is $\hat{\delta} \hat{\gamma}$, which is also equal to $\hat{\eta} \hat{\gamma}^{*}$ from (7). Since $\hat{\eta}$ is always negative (unless $\mu_{1}=\mu_{2}$ ), the magnitude of poverty reduction will be a monotonically increasing function of $\hat{\gamma}^{*}$; the larger $\hat{\gamma}^{*}$, the greater will be the percentage reduction in poverty between the two periods. Thus, maximizing $\hat{\gamma}^{*}$ will be equivalent to maximizing the percentage reduction in poverty.

To determine if growth is absolutely pro-poor, it will require a consistent estimate of $\eta^{*}$, which can be estimated as

$$
\hat{\eta}^{*}=\frac{1}{2}\left[\ln \left(\theta\left(z, \tilde{x}_{1}+\mu_{2}-\mu_{1}\right)\right)-\ln \left(\theta\left(z, \tilde{x}_{1}\right)\right)+\ln \left(\theta\left(z, \tilde{x}_{2}\right)\right)-\ln \left(\theta\left(z, \tilde{x}_{2}-\mu_{2}+\mu_{1}\right)\right)\right] / \hat{\gamma}
$$

\section{REFERENCES}

Datt, G. and M. Ravallion, "Growth and Redistribution Components of Changes in Poverty Measures: A Decomposition with Applications to Brazil and India in the 1980s," Journal of Development Economics, 38, 275-95, 1992.

Dollar, D. and A. Kraay, "Growth is Good for the Poor," Journal of Economic Growth, 7, 195-225, 2002.

Eastwood, R. and M. Lipton, "Pro-Poor Growth and Pro-Growth Poverty Reduction: Meaning, Evidence and Policy Implications," Asian Development Review, 19, 1-37, 2001.

Ferreira, F., P. Lanjouw, and M. Neri, "A Robust Poverty Profile for Brazil using Multiple Data Sources," Revista Brasileira de Economia, 57(1), 59-92, 2003.

Foster, J., J. Greer, and E. Thorbecke, "A Class of Decomposable Poverty Measures," Econometrica, 52(3), 761-6, 1984.

Grosse, M., K. Harttgen, and S. Klasen, "Measuring Pro-Poor Growth in Non-Income Dimensions," World Development, 36(3), 1021-47, 2008.

${ }^{10}$ Kakwani (2000) justified this decomposition using an axiomatic approach. Kraay (2004) estimated the growth and inequality effects using Datt and Ravallion's (1992) poverty decomposition, which consists of three components: growth component, inequality component and a residual term. He calls this decomposition the discrete-time analog of (A.3). Equation (A.3) consists of only growth and inequality components. Thus, estimating (A.3) using a discrete-time analog with three components will give inconsistent estimates of growth and inequality components. 
Kakwani, N., "Poverty and Economic Growth with Application to Côte d'Ivoire," Review of Income and Wealth, 39(2), 121-39, 1993.

- "Growth and Inequality Components of Change in Poverty with Application to Thailand," Journal of Quantitative Economics, 16(1), 67-80, 2000.

Kakwani, N. and E. Pernia, "What is Pro-Poor Growth," Asian Development Review, 16(1), 1-22, 2000.

Klasen, S., "In Search of the Holy Grail: How to Achieve Pro-Poor Growth?" Discussion Paper No. 96, Ibero-America Institute for Economic Research, Georg-August-University, Gottingen, 2003.

Kraay, A., "When is Growth Pro-Poor? Cross-Country Evidence," IMF Working Paper No. 47, International Monetary Fund, Washington DC, 2004.

McCulloch, N. and B. Baulch, "Tracking Pro-Poor Growth," ID21 Insights No. 31, Institute of Development Studies, Sussex, 1999.

Ravallion, M. and S. Chen, "Measuring Pro-Poor Growth," Economics Letters, 78, 93-9, 2003.

Neri, M., "Aspectos Fiscais e Sociais de Modalidades Alternativas de Reajuste de Aposentadorias e Pensões Públicas,” in Coleção Previdência Social: Previdência, Assistência Social e Combate à Pobreza/Série Debates, Vol. 3, 113-21, 2001.

Son, Hyun H., "A Note on Pro-Poor Growth,” Economics Letters, 82, 307-14, 2004.

Son, Hyun H. and N. Kakwani, "Global Estimates of Pro-Poor Growth," World Development, 36(3), 1048-66, 2008.

Watts, H. W., “An Economic Definition of Poverty,” In D. Moynihan (ed.), Understanding Poverty, Basic Books, New York, 1968. 